\title{
SCOLIOSIS AND NEUROFIBROMATOSIS *
}

\author{
J. C. SCOtT, Oxford, England \\ From the Nuffield Orthopaedic Centre, Oxford
}

The high proportion of scoliosis classed as idiopathic has presented the major challenge to the understanding of this condition. Clarification of the natural history of various types has made some contribution to the understanding of etiology and has determined the necessity for treatment.

The varieties defined include congenital (Scott 1962), infantile alignment (Scott 1956), resolving and progressive infantile idiopathic (Scott and Morgan 1955), juvenile and adolescent idiopathic. It has also been pointed out that beyond the infantile period the vicious circle concept of idiopathic scoliosis does not necessarily apply, and that spontaneous regression may occur (Scott 1959).

One variety of scoliosis which has been accepted as an etiological entity, without accurate definition, is that associated with neurofibromatosis. It has been suggested by various workers that there is a typical von Recklinghausen's scoliosis; my ignorance stimulated enquiry into the problem. There seemed to be two methods of approach: the first, to examine a number of patients with neurofibromatosis, and the second, to

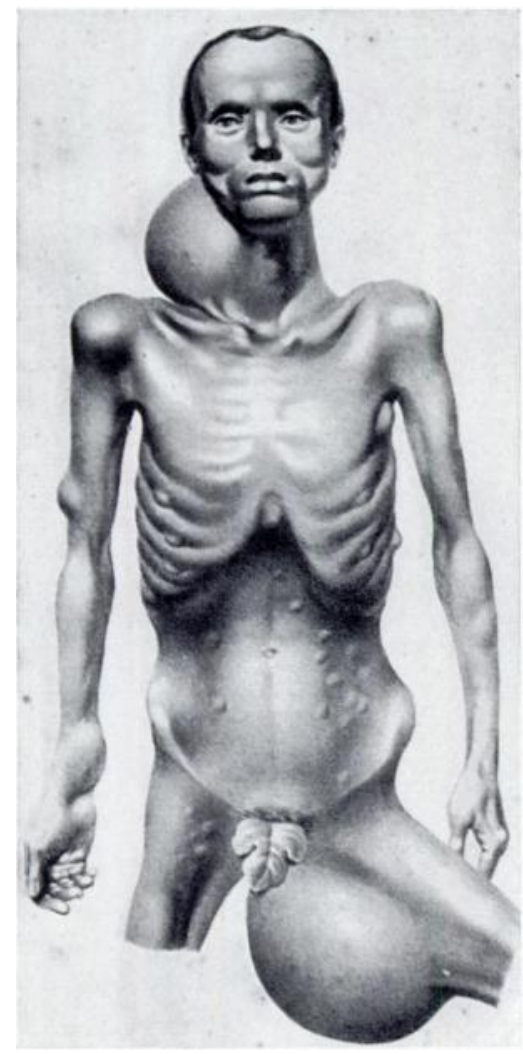

FIG. 1

From R. W'. Smith`s (1849) monograph. A paticnt with many tumours. examine all available examples of scoliosis in von Recklinghausen's disease.

It is essential to look a little at the disease itself to sift and summarise the knowledge already available. Description of the condition begins about the end of the eighteenth century. Smith (1849) accurately recorded the physical and necropsy findings in many cases and also gave a list of some seventy-five references. The origin of neurofibroma was taken to be a recognisable nerve trunk, and Smith"s comment on the source was: "Although the pathologists have hitherto failed to discover anything like nervous structure in these tumours I still incline to the opinion that they are connected with the minute filaments and ultimate ramifications of the nerves." Virchow (1863) described the pathology and established that these were true tumours, distinct from, for example, the amputation neuroma.

Von Recklinghausen`s principal contributions (1882) were the demonstration of nerve elements in the fibrous tissue tumours and the association of the nervous and dermal connection. The condition was already accepted as a congenital abnormality, and Payne (1887) suggested an embryological failure at the meso-ectodermal junction as the determining cause. This idea, modified by some further knowledge, remains the generally accepted view of the pathogenesis. The three further important contributions to the knowledge of the disease are: 1) Chauffard's (1896) assertion that the pigmented areas were as

\footnotetext{
* Paper read at the Combined Meeting of the Orthopaedic Associations, Vancouver, June 1964.
} 
characteristic of the disease as the tumours, and frequently associated; 2) Robb-Smith and Pennybacker's (1952) demonstration that the disease was transmitted by a dominant gene but was not sex-linked; and 3) Penfield and Young's (1930) observation that the appearance and development of tumours and pigmentation were associated with activities of the sex hormones.

With regard to the skeletal manifestations it is interesting that Smith, with his careful anatomical description of necropsy findings-including one in which there were said to be 2,000 tumours (Fig. 1)-made no mention of involvement of the skeleton. Adrian (1901) first mentioned skeletal lesions in neurofibromatosis and many others have since made observations on this aspect of the syndrome. There are few fully documented examples of spinal deformity in the literature and those collectively show no standard pattern. Carrière, Huriez, Gervois and Dupret (1938) described kyphoscoliosis as the main deformity of the spine. That there may be widespread and variable changes in the skeleton is not in doubt. The cause of these changes and how they contribute to spinal deformity remains obscure.

In the analysis of the material available there were therefore three main points for elucidation: 1) the incidence of spinal deformity in von Recklinghausen's disease; 2) whether
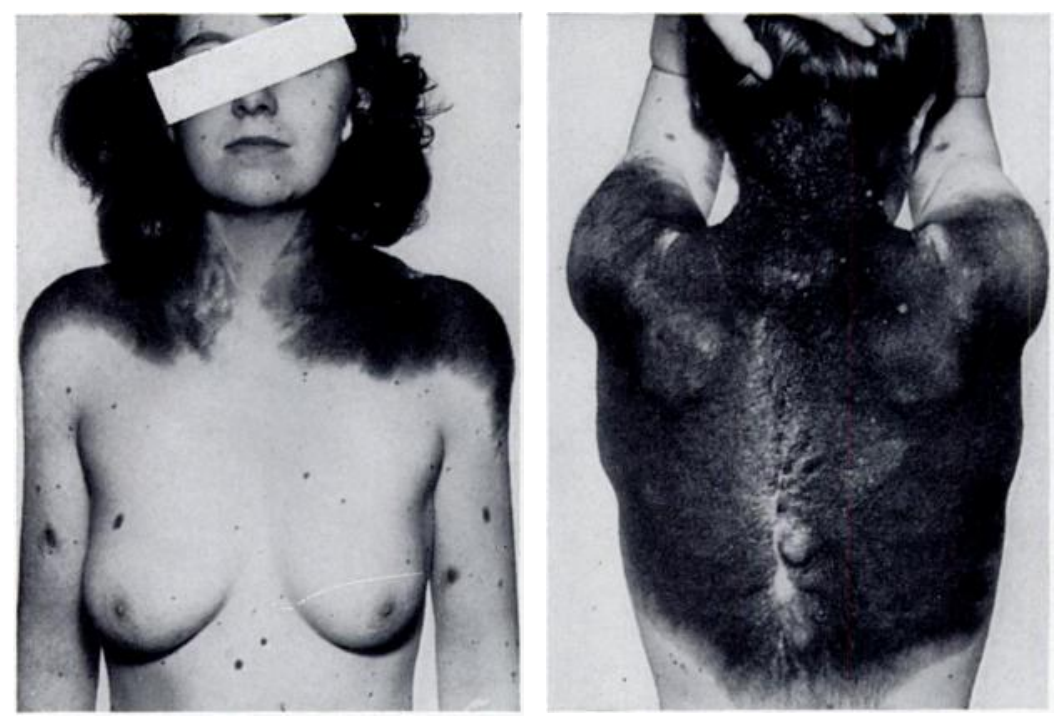

Fig. 2

Case 1-Woman of 25 years with gross skin markings and innumerable small tumours, but without spinal deformity.

any pattern of behaviour was evident in scoliosis associated with this condition; and 3) what etiological factors, if any, could be adduced relating the disease and the deformity.

With generous cooperation of my colleagues at the Radcliffe Infirmary, Oxford, 123 patients were reviewed, of whom eighty-one had undoubted neurofibromatosis. These eightyone patients with multiple tumours were analysed, and it was found that sixty-one had caféau-lait markings and sixteen had " curvature " of the spine. Of these, six had lateral curvature of less than 30 degrees with little or no rotation; ten had curves ranging from 30 degrees to 90 degrees.

From the records of the orthopaedic hospital, where significant café-au-lait marking was listed under the diagnostic heading of von Recklinghausen's disease in scoliosis, there were an additional seventeen patients who had either café-au-lait spots only, or café-au-lait spots and a single tumour, all with spinal deformities. Of these seventeen, three had curves of less than 30 degrees. 
The first group gives an indication of the incidence of spinal deformity in those seeking hospital treatment for von Recklinghausen's disease. The frequency of café-au-lait spots as a single sign of von Recklinghausen's disease, and the absence of symptoms associated with them, makes any reliable estimate of the incidence of spinal deformity with café-au-lait markings impossible to assess, but having regard to the frequency with which these are seen it must be very small.

Analysis of the spinal deformities led to some positive and negative conclusions. There was no association between the number of tumours or the extent of the skin marking and the incidence of spinal deformity (Fig. 2). There was only one patient among the thirty-three

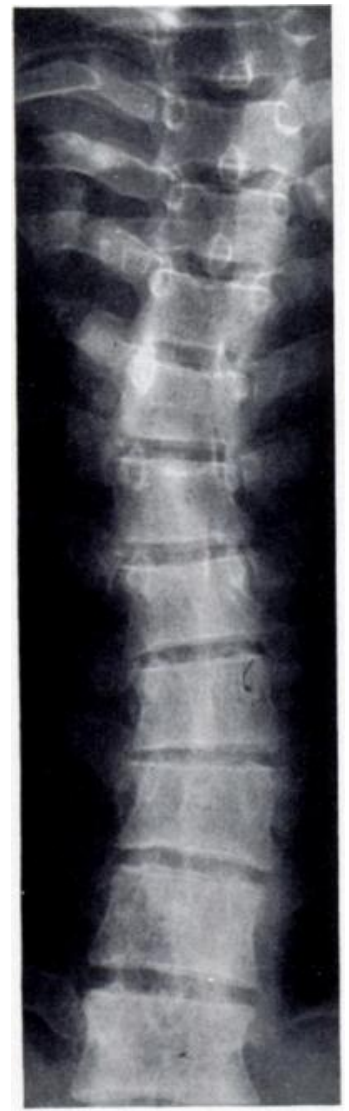

FIG. 3

Case 2-Man of 30 years with multiple tumours, including extradural tumour at the fourth thoracic level. with spinal deformity who had no café-au-lait marking. There were nine in whom this was the only evidence of von Recklinghausen's disease. Spinal deformity was therefore more consistently associated with the skin markings than with multiple tumours. In the nine patients with spinal curves measuring less than 30 degrees six had spinal tumours (Fig. 3) and two had meningeal abnormalities demonstrated by myelography (Figs. 4 and 5).

In the patients with the more severe spinal deformities there was a wide variety of curve patterns. In three the curve was in the cervico-thoracic region (Fig. 6), in thirteen in the thoracic region (Figs. 7 and 8) and in eight it was thoraco-lumbar (Figs. 9 and 10). There was no uniformity in length or direction of the thoracic curves. They varied from four vertebrae to ten vertebrae in length. Seven had the convexity of the curve to the right and five to the left, and in one there was a double primary thoracic curve (Fig. 11). The degree of rotation varied in general with the severity of the lateral curve, but in five patients the kyphosis was the major element of the deformity. In seven cases the curves were morphologically of the congenital type, and in these there was other evidence of congenital abnormality - fused ribs, hemivertebrae and lumbo-sacral developmental anomalies (Fig. 12). In all these mature patients the severity of the curves varied enormously; among those with curves of 30 degrees or more it ranged from 34 degrees to 90 degrees. In eleven the curve was 70 degrees or less, in eight it was 90 degrees or more, and in five the kyphosis was severe.

When we look at the factors involved in this disease it is perhaps not surprising that there is no standard pattern of spinal deformity. Here we have a congenital abnormality with a hereditary background -a circumstance thought to potentiate teratogenesis; a condition which may not appear till determined by endocrine factors, such as puberty or precocious puberty (Fig. 13), pregnancy, menopause, one in which any tissue may be involved-by overgrowth, agenesis, direct pressure and in other ways.

Apart from the effects of dysgenesis and direct pressure, certain local changes are described in bone. These are related to long bones, but no evidence has been produced of primary involvement of bone leading to spinal deformity.

A search for any generalised involvement of bone likely to provide a common factor which might exert a predictable effect on the spine has been fruitless. The view put forward by Carrière et al. (1938) that neurofibroma is a clinical syndrome which may manifest itself in different organs simultaneously or may occur only in one or other organ of the body, leads to a convenient classification into five different types but throws no more light on the problem of spinal deformity. For example, the osseous syndrome might be expected to include 


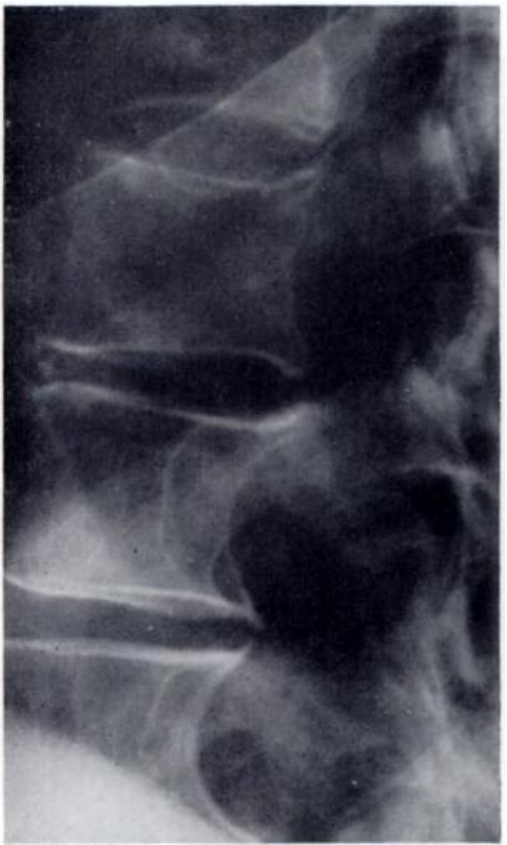

Fig. 4

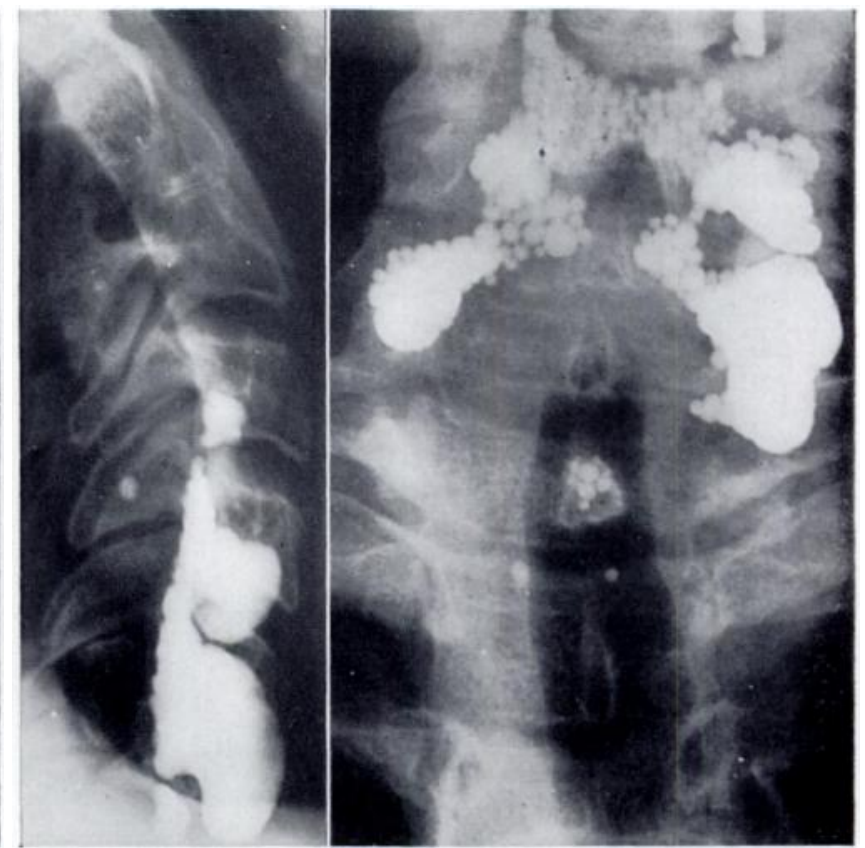

FIG. 5

Figure 4-Case 3. Woman of 48 years. Scalloping of vertebral bodies, associated with antero-lateral meningocele. Figure 5-Case 4. Man of 47 years. Antero-lateral meningoceles in the cervical region, without lateral curvature.
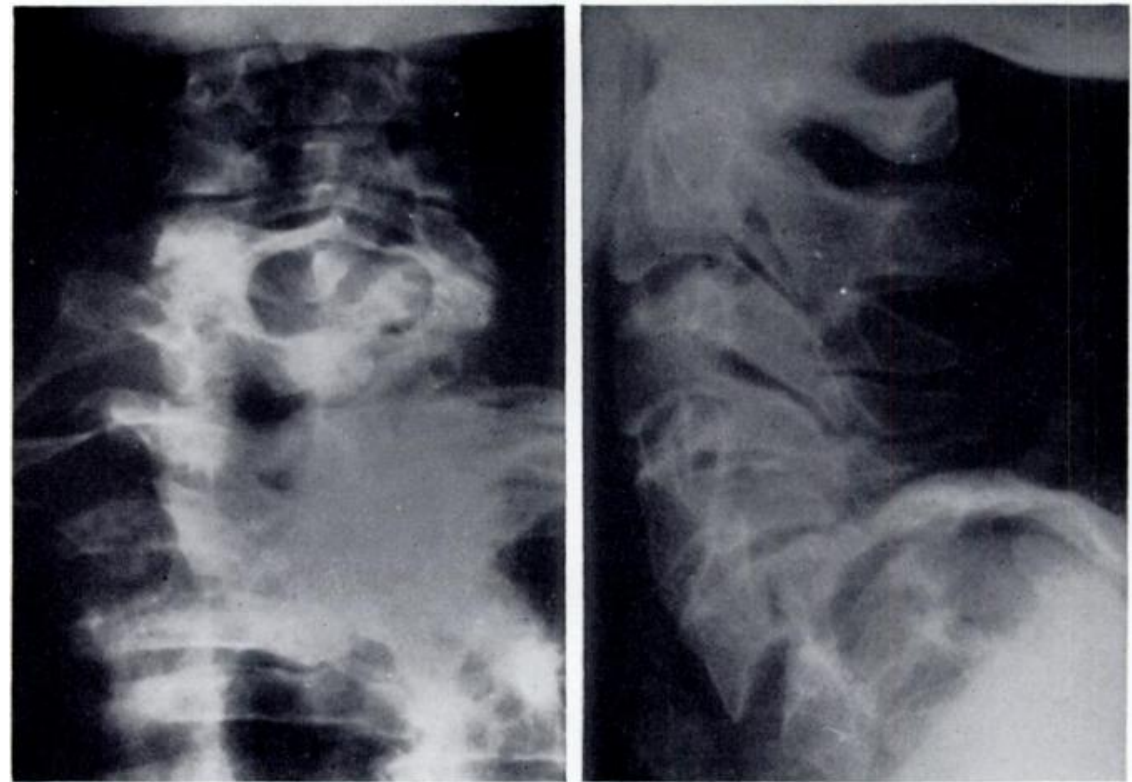

Fig. 6

Case 5-Woman of 42 years. Cervico-thoracic kyphoscoliosis to the left with dislocation. 


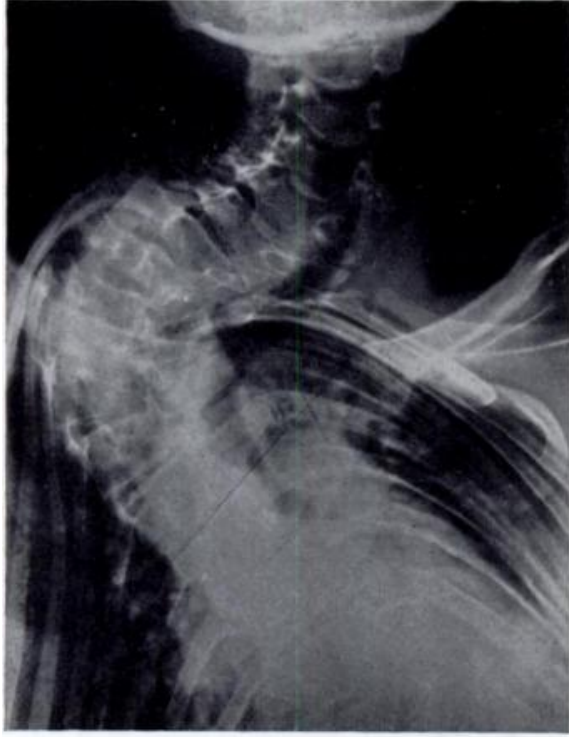

Fig. 7

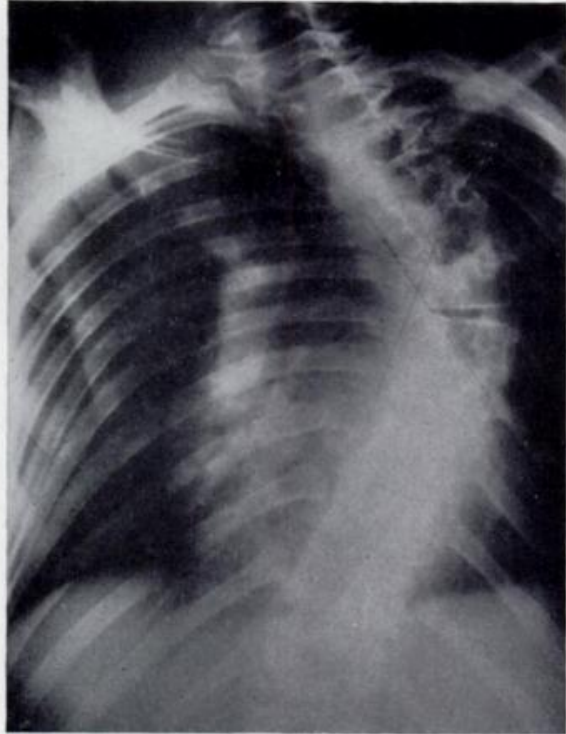

FiG. 8

Figure 7-Case 6. Man of 19 years. Severe high thoracic scoliosis to the right. Figure 8Case 7. Youth aged 16 years. Mid-thoracic scoliosis to the left.

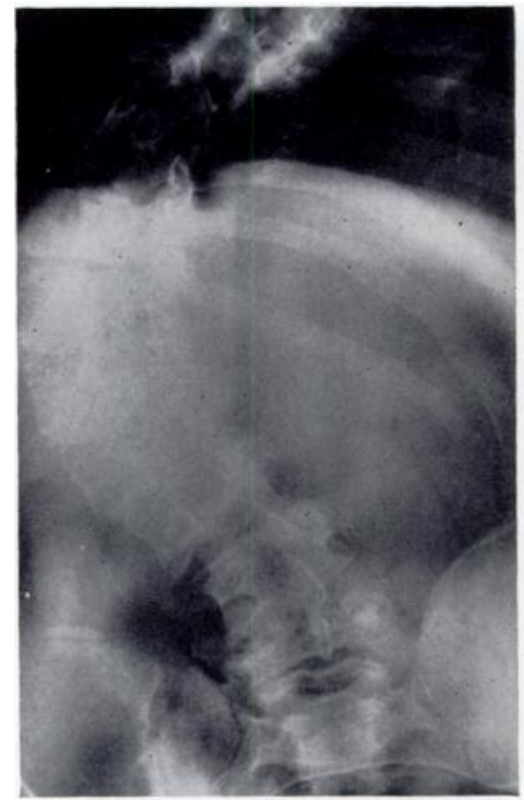

FiG. 9

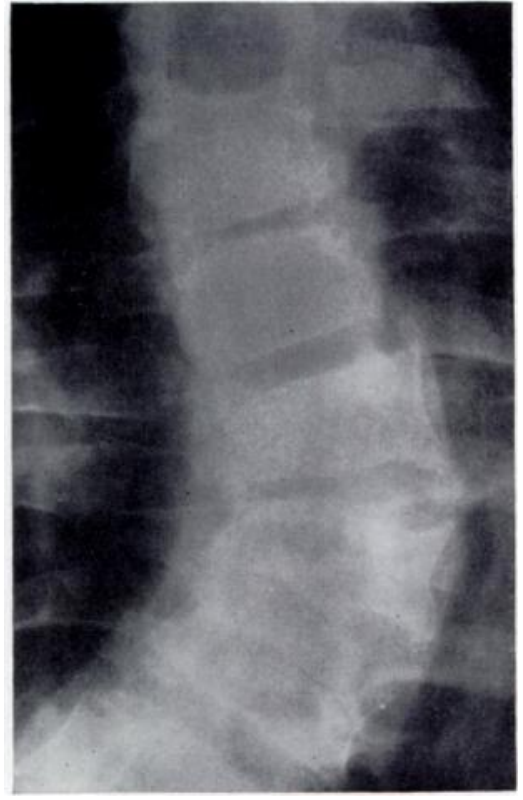

Fig. 10

Figure 9-Case 8. Man of 18 years. Thoraco-lumbar scoliosis to the right. Figure 10-Case 9. Man of 19 years. Four vertebrae involved: eighth to eleventh thoracic. Sixty-degree curve to left. 


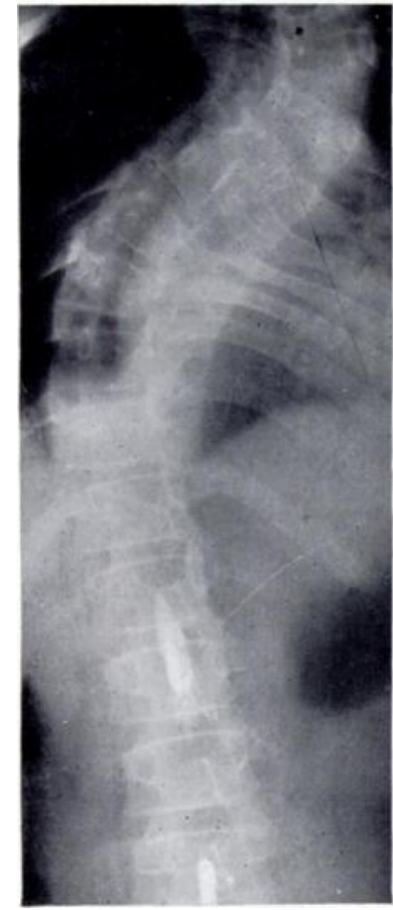

Fig. 11

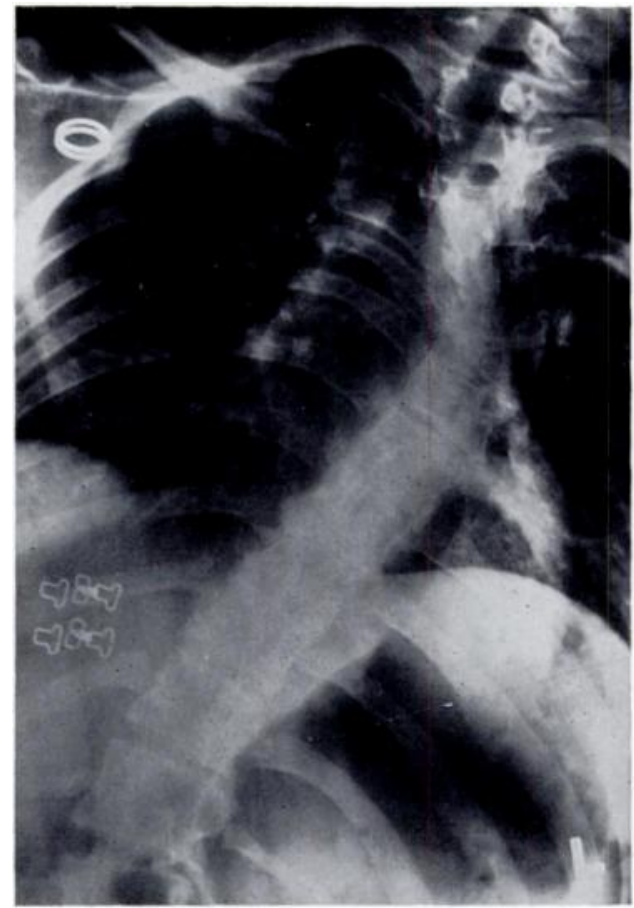

Fig. 12

Figure 11-Case 10. Girl of 7 years. Double structural thoracic curve. Figure 12Case 11. Girl of 16 years. Wedging of thoracic vertebrae with fusion of left middle ribs. Forty-degree curve.

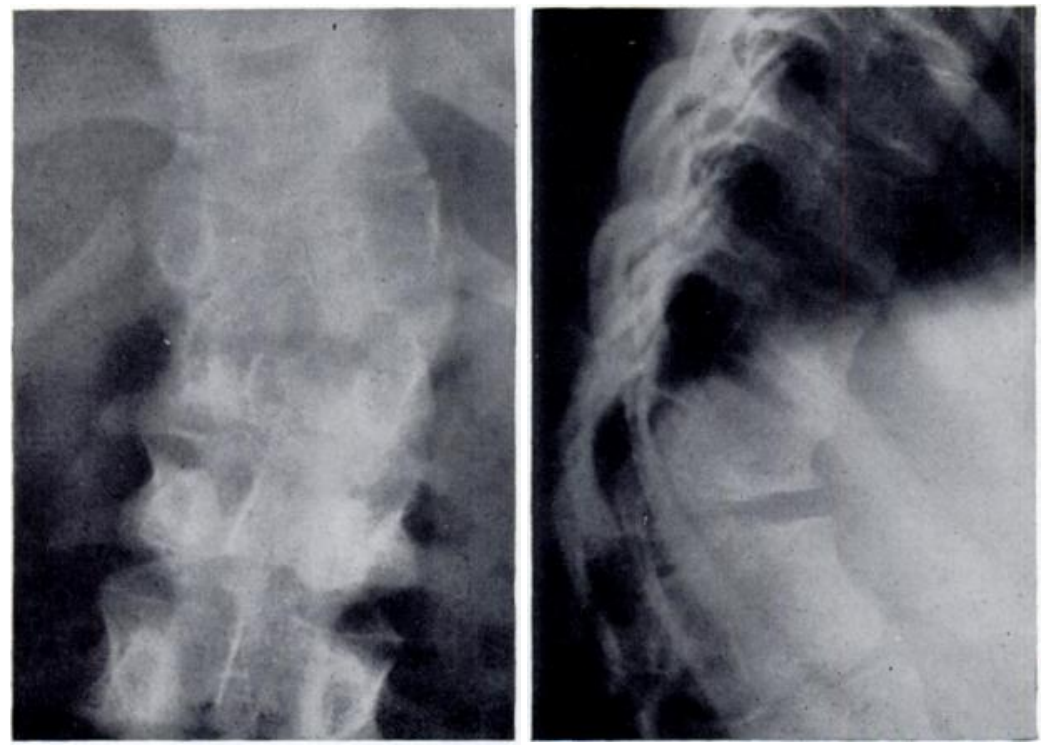

Fig. 13

Case 12-Girl of 14 years. Menses began at 9 years (family average 13 years). No other signs of von Recklinghausen's disease. 
all the varieties of skeletal involvement, but in these thirty-three patients with scoliosis there was no example of gigantism, pseudarthrosis or other primary skeletal abnormality. Thannhauser (1944), in reiterating the significance of the deposits of melanin in the basal layers which constitute the café-au-lait spots, said that not only were they diagnostic of von Recklinghausen's disease, but that they indicated a search for hidden involvement in other organs, especially for lesions in bone. The results of these investigations support that injunction.

\section{SUMMARY}

1. Analysis of eighty-one patients with neurofibromatosis showed that sixty-two (76 per cent) had café-au-lait markings; 12 per cent had significant spinal deformity.

2. Thirty-three examples of spinal deformity in neurofibromatosis showed a wide variety of patterns and severity of the adult curve. There was no evidence that there was any recognisable pattern of scoliosis in neurofibromatosis. No evidence was discovered to suggest that any acquired local abnormality of bone contributed to the deformity.

3. Some of the severe deformities showed a pattern similar to that seen in the congenital scolioses, and this might be the link between the neurofibromatosis and the spinal deformity.

\section{REFERENCES}

Adrian, C. (1901): Ueber Neurofibromatose und ihre Komplikationen. Beiträge zur Klinischen Chirurgie, $31,1$. Brooks, B., and Lehman, E. P. (1924): The Bone Changes in Recklinghausen's Neurofibromatosis. Surgery, Gynecology and Obstetrics, 38, 587.

Carrière, G., Huriez, A. C., Gervois, M., and Dupret, R. (1938): La gliofibromatose de Recklinghausen. Paris: Doin et Cie.

Chauffard, A. (1896): Dermo-fibromatose pigmentaire (ou neuro-fibromatose généralisée). Mort par adénome des capsules surrénales et du pancréas. Bulletins et Mémoires de la Société Médicale des Hôpitaux de Paris, Troisième Série, 13, 777.

Gould, E. P. (1918): The Bone Changes Occurring in von Recklinghausen's Disease. Quarterly Journal of Medicine, 11, 221.

Holt, J. F., and Wright, E. M. (1948): The Radiologic Features of Neurofibromatosis. Radiology, 51, 647.

LÉger, L. (1949): Maladies du squelette. Paris: Masson et Cie.

McCarroll, H. R. (1950): Clinical Manifestations of Congenital Neurofibromatosis. Journal of Bone and Joint Surgery, 32-A, 601.

Payne, J. F. (1887): Multiple Neuro-fibromata in Connection with Molluscum Fibrosum. Transactions of the Pathological Society of London, 38, 69.

Penfield, W., and Young, A. W. (1930): The Nature of von Recklinghausen's Disease and the Tumors Associated with it. Archives of Neurology and Psychiatry, 23, 320.

von Recklinghausen, F. D. (1882): Ueber die multiplen Fibrome der Haut und ihre Beziehung zu den multiplen Neuromen. Berlin: Hirschwald.

Robb-Smith, A. H. T., and Pennybacker, J. (1952): Von Recklinghausen's Disease (Neurofibromatosis). In British Encyclopaedia of Medical Practice. Second edition, Vol. 10. London: Butterworth \& Co. (Publishers) Ltd.

Scort, J. C. (1956): Differential Diagnosis of Infantile Scoliosis. Proceedings of the Royal Society of Medicine (Section of Orthopaedics), 49, 398.

Scort, J. C. (1959): Resolving Scoliosis. Journal of Bone and Joint Surgery, 41-B, 105.

Scort, J. C. (1962): The Natural History of Congenital Scoliosis. Presidential Address. Proceedings of the Royal Society of Medicine (Section of Orthopaedics), 55, 839.

Scort, J. C., and Morgan, T. H. (1955): The Natural History and Prognosis of Infantile Idiopathic Scoliosis. Journal of Bone and Joint Surgery, 37-B, 400.

Sмiтh, R. W. (1849): A Treatise on the Pathology, Diagnosis and Treatment of Neuroma. Dublin: Hodges \& Smith.

ThanNhauser, S. J. (1944): Neurofibromatosis (von Recklinghausen) and Osteitis Fibrosa Cystica Localisata et Disseminata (von Recklinghausen). Medicine, Baltimore, 23, 105.

VIRCHOw, R. (1863): Die krankhaften Geschwülste, 3, 233. Berlin: A Hirschwald.

Weiss, R. S. (1921): (A) von Recklinghausen's Disease in the Negro; (B) Curvature of the Spine in von Recklinghausen's Disease. Archives of Dermatology and Syphilology, 3, 144. 